\title{
Assessment of retroperitoneal lymph node status in locally advanced cervical cancer
}

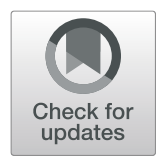

Wei $\mathrm{Li}^{1 \dagger}$, Li Xiong ${ }^{1 \dagger}$, Qiaoling Zhu' ${ }^{1}$, Hong Lu², Meiling Zhong ${ }^{3}$, Meirong Liang ${ }^{3}$, Wei Jiang ${ }^{3}$, Yanan Wang ${ }^{3}$ and Wei Cheng ${ }^{1 *}$

\begin{abstract}
Background: The assessment of retroperitoneal lymph node status in patients with locally advanced cervical cancer is still a problem. This study aimed to explore the choice of these assessment methods.

Methods: Laparoscopic retroperitoneal lymphadenectomy was performed in 96 patients with advanced cervical cancer. The positive rates of lymph node metastasis were analyzed. The values of computed tomography lymph node minimum axial diameter (MAD) and squamous cell carcinoma antigen (SCC-Ag), and their combination in predicting retroperitoneal lymph node metastasis were compared. High-risk factors for common iliac lymph node (CILN) and/or para-aortic lymph node (PALN) metastasis were analyzed.

Results: The lymph node metastasis rate was $62.50 \%$ and the CILN and/or PALN metastasis rate was 31.25\%. Overall, 96 patients had 172 visible lymph nodes. The positive rate of lymph node metastasis was significantly higher in the MAD $\geq 1.0 \mathrm{~cm}$ group (83.33\%) than in the $0.5 \mathrm{~cm} \leq \mathrm{MAD}<1.0 \mathrm{~cm}$ group (26.82\%). The critical values of MAD and SCC-Ag in determining lymph node metastasis were $1.0 \mathrm{~cm}$ and $5.2 \mathrm{ng} / \mathrm{mL}$, respectively. The accuracy, specificity, and Youden index of MAD $\geq 1.0 \mathrm{~cm}$ combined with $\mathrm{SCC}-\mathrm{Ag} \geq 5.2 \mathrm{ng} / \mathrm{mL}$ for evaluating lymph node metastasis were $75.71 \%, 100 \%$, and 0.59 , respectively, and were significantly different from the values for the MAD $\geq 1.0 \mathrm{~cm}$ (72.09\%, 80.56\%, and 0.47, respectively) and SCC-Ag $\geq 5.2 \mathrm{ng} / \mathrm{mL}$ (71.43\%, 68.97\%, and 0.42 , respectively) groups. Correlation analysis showed that non-squamous cell carcinoma, pelvic lymph node (PLN) MAD $\geq 1.0 \mathrm{~cm}$ plus number $\geq 2$, and 1 PLN MAD $\geq 1.0 \mathrm{~cm}$ with CILN and/or PALN MAD $0.5-1.0 \mathrm{~cm}$ were risk factors for CILN and/or PALN metastasis.

Conclusion: Patients with MAD $\geq 1.0 \mathrm{~cm}$ and SCC-Ag $\geq 5.2 \mathrm{ng} / \mathrm{mL}$, as well as high risk factors for CILN and/or PALN metastasis, should undergo resection of enlarged lymph nodes below the common iliac gland and lymphadenectomy of CILN/PALN to reduce tumor burden and to clarify lymph node metastasis status for accurate guidance in follow-up treatment. Patients with MAD $<1.0 \mathrm{~cm}$ and SCC-Ag $<5.2 \mathrm{ng} / \mathrm{mL}$ may be treated with chemoradiotherapy directly based on imaging, given the low lymph node metastasis rate.
\end{abstract}

Keywords: Retroperitoneal lymph node, Cervical neoplasm, Computed tomography (CT), Squamous cell carcinoma antigen (SCC-Ag)

\footnotetext{
* Correspondence: 837612407@qq.com

${ }^{\dagger}$ Wei Li and Li Xiong contributed equally to this work.

'Department of Gynecology, Hunan Maternal and Child Health Hospital, Changsha, Hunan, China

Full list of author information is available at the end of the article
}

(C) The Author(s). 2021 Open Access This article is licensed under a Creative Commons Attribution 4.0 International License, which permits use, sharing, adaptation, distribution and reproduction in any medium or format, as long as you give appropriate credit to the original author(s) and the source, provide a link to the Creative Commons licence, and indicate if changes were made. The images or other third party material in this article are included in the article's Creative Commons licence, unless indicated otherwise in a credit line to the material. If material is not included in the article's Creative Commons licence and your intended use is not permitted by statutory regulation or exceeds the permitted use, you will need to obtain permission directly from the copyright holder. To view a copy of this licence, visit http://creativecommons.org/licenses/by/4.0/ The Creative Commons Public Domain Dedication waiver (http://creativecommons.org/publicdomain/zero/1.0/) applies to the data made available in this article, unless otherwise stated in a credit line to the data. 


\section{Background}

In 2018, the International Federation of Gynecology and Obstetrics (FIGO) officially included the status of lymph node metastasis in the clinical staging of cervical cancer [1]. Lymph node metastasis is one of the independent prognostic factors for cervical cancer and the lymph node metastasis rate directly parallels the clinical stage. For example, the probabilities of pelvic lymph node (PLN) and para-aortic lymph node (PALN) metastases in patients with stage IB are 11$20 \%$ and $2-7 \%$, respectively, and these increase in phase II to $36-45 \%$ and $7.2-25 \%$, respectively, while phase III levels reach as high as $40-71 \%$ and $21-37 \%$, respectively [2-4]. Patients with common iliac lymph node (CILN) and/or PALN metastasis are treated by extended abdominal radiotherapy in the para-aortic lymphatic drainage area [5]. Concurrent chemoradiotherapy is the standard treatment mode for locally advanced cervical cancer. The radiotherapy dose and radiation field range determine the therapeutic effect, but inadequate sensitivity and specificity can limit the use of radiotherapy and chemotherapy.

The lymph node status is typically evaluated by computed tomography (CT), magnetic resonance imaging (MRI), and positron emission tomography/computed tomography (PET-CT) [6]. The sensitivity of CT for detecting metastatic lymph nodes is only about $60 \%$. By contrast, the sensitivity and specificity of MRI for judging parametrial infiltration and bladder and rectum invasion are good, but the diagnostic value of metastatic lymph node imaging is limited, with a sensitivity of only $30 \%$ [7-9]. Similarly, even the most accurate diagnosis of lymph nodes by PET-CT still has a high false-positive rate [10]. Therefore, the broad use of imaging-guided radiotherapy inevitably has problems [11].

When conducted prior to radiotherapy treatment, laparoscopic retroperitoneal lymphadenectomy can clarify the status of lymph node metastasis, remove the enlarged lymph nodes that are difficult to cure by radiotherapy, provide accurate guidance for the follow-up treatment of patients, and allow a more accurate assessment of the patient's prognosis [12, 13]. However, retroperitoneal lymphadenectomy increases the patient's surgical complications and hospitalization costs to some extent $[14,15]$. Therefore, the decision to perform retroperitoneal lymph node resection before radiotherapy needs to be individualized with an auxiliary examination. How to shunt patients with locally advanced cervical cancer according to the auxiliary examination is an urgent problem to be solved. The aim of the present study was to investigate the available options for assessing the status of retroperitoneal lymph node status in locally advanced cervical cancer to ensure optimal treatment.

\section{Methods}

\section{Clinical data}

This study was approved by the Ethics Committee of the Hunan Maternal and Child Health Hospital. All patients provided signed informed consent.

A total of 96 patients with locally advanced cervical cancer who underwent laparoscopic retroperitoneal lymphadenectomy at the Oncology Department of Hunan Maternal and Child Health Hospital from March 2011 to October 2018 were enrolled. The patient age ranged from 23 to 65 years, with a median age of 48 years. The cases included 12 IB2 stage, three IIA2 stage, 48 IIB stage, two IIIA stage, and 31 IIIB stage cervical cancers. In addition, the study population included 86 cases of squamous cell carcinoma and 10 cases of nonsquamous cell carcinoma (five cases of adenocarcinoma, four cases of adenosquamous cell carcinoma, and one case of neuroendocrine small cell carcinoma). A flowchart of the study is shown in Fig. 1.

\section{Inclusion criteria}

The patients were included in the study if they had stage IB2-IIIB cervical cancer (FIGO 2009); had not undergone any preoperative radiotherapy, chemotherapy or operative contraindication; had signed an informed consent form; had undergone a comprehensive preoperative assessment (i.e., medical history inquiry, physical examination, squamous cell carcinoma-related antigen [SCCAg] detection, and imaging examination); and had their preoperative and postoperative pathology confirmed by two senior pathologists.

\section{Exclusion criteria}

Patients were excluded from the study if they had undergone preoperative radiotherapy or chemotherapy or had distant metastasis indicated by imaging.

\section{Surgical methods}

We performed laparoscopic resection of the PLNs and PALNs $[16,17]$. The upper boundary of PLN resection was the abdominal aorta bifurcation, and the lower boundary was the deep circumflex iliac vein across the external iliac artery. PALN resection ranged from the abdominal aorta bifurcation to the area of the inferior mesenteric artery. The lymph nodes were marked according to the surgical site and then sent for examination. Each lymph nodes were sectioned and examined by routine hematoxylin and eosin $(\mathrm{H} \& \mathrm{E})$ staining for presence/absence of lymph node metastasis.

\section{Enhanced preoperative spiral computed tomography examination}

Before the operation, all patients underwent whole abdominal enhanced spiral CT with a Siemens 16-slice 


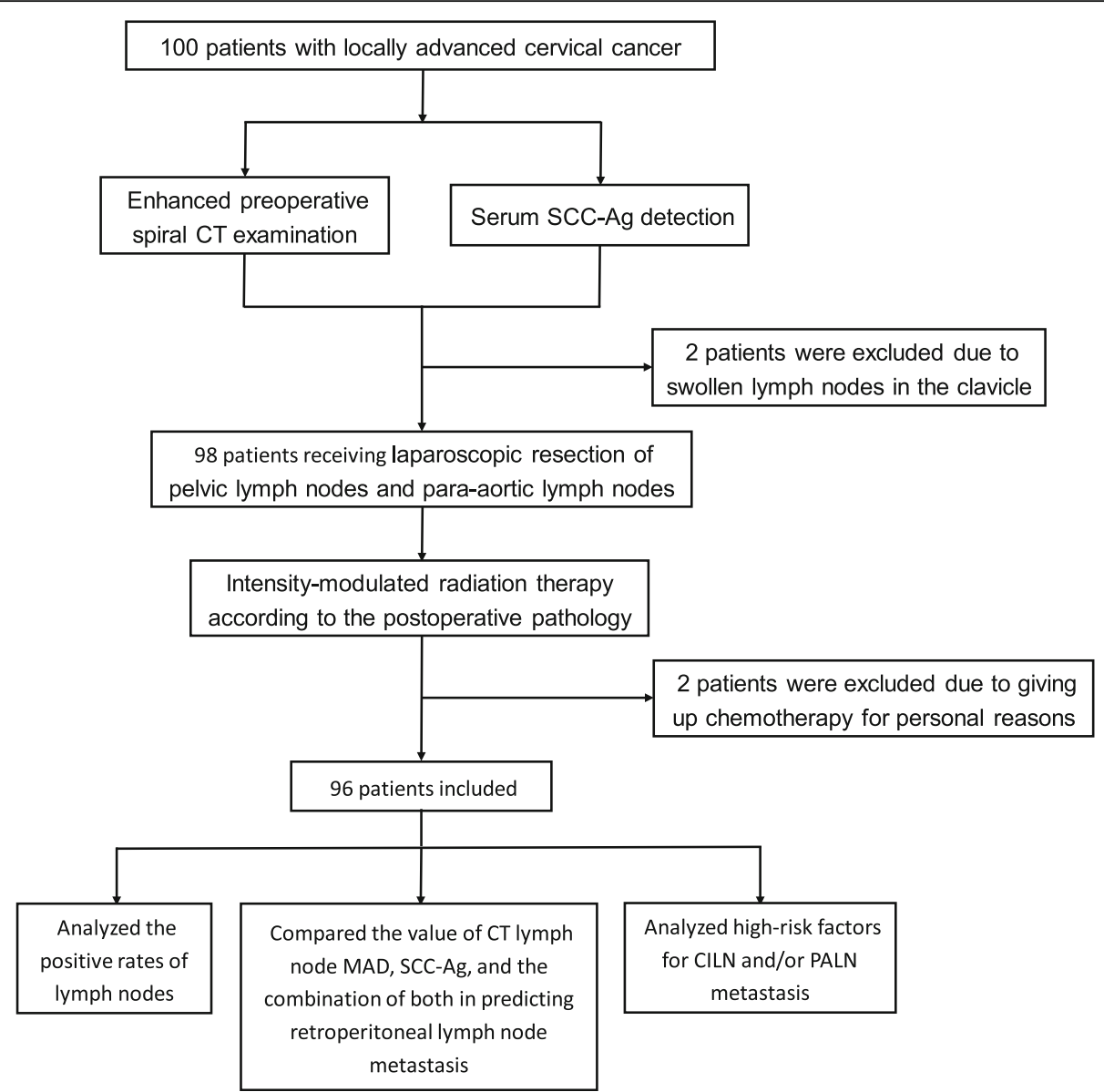

Fig. 1 Flowchart of the study. CT, computed tomography; SCC-Ag, squamous cell carcinoma antigen; MAD minimum axial diameter; CILN, common iliac lymph node; PALN, para-aortic lymph node

spiral CT system. The scanning thickness and interval were $5 \mathrm{~mm}$, and the scanning range extended from the diaphragm top to the vulva area. A reinforcing agent consisting of $70-90 \mathrm{~mL}$ of non-ionic contrast agent was injected via the elbow vein at a rate of $3.5 \mathrm{~mL} / \mathrm{s}$, with delayed scanning of $30 \mathrm{~s}$ [18].

\section{CT evaluation method}

The CT imaging data of all patients (96 cases) were reviewed by radiologists and radiotherapists. The PLNs and PALNs were grouped based on the Radiation Therapy Oncology Group (RTOG) classification. The PLNs were divided into left and right sides, and each side was separated into five parts: total iliac, internal iliac, external iliac, presacral, and obturator. The minimum axial diameter (MAD) of the PALN and PLN cross-section was measured. The retroperitoneal lymph nodes detected on CT images were compared with the postoperative pathology. The pathological findings of retroperitoneal lymph nodes were used as the gold standard to judge the accuracy of CT diagnosis $[15,16]$.

\section{Serum SCC-Ag detection}

A total of $3 \mathrm{~mL}$ of venous blood was collected before treatment. Serum SCC-Ag concentration was detected by microparticle enzyme immunoassay using Abbott's fully automatic fluorescent enzyme label analyzer. Briefly, in the first step, the sample and the SCC antibody-coated paramagnetic microparticles were mixed and the SCC antigen in the sample was allowed to bind to the SCC antibody-coated microparticles. After rinsing, an acridinium ester-labeled SCC antibody conjugate was added to form a reaction mixture. After further rinsing, the pre-excitation liquid and the excitation liquid were added to the reaction mixture. The resulting chemiluminescent reactions were measured and expressed as relative luminescence units (RLUs). The SCC antigen in the sample was directly proportional to the RLU value detected by the optical system [19].

\section{Radiotherapy}

All patients underwent Intensity-Modulated Radiation Therapy (IMRT) according to their postoperative 
pathology. The target area for radiotherapy was delineated according to the consensus of the target area for RTOG cervical cancer. The IMRT plan was designed using the Pinnacle planning system (Philips, Netherlands, version 9.7).

\section{Statistical analysis}

All data were analyzed using the Chi-squared $\left(x^{2}\right)$ test in the SPSS (Version 17.0) statistical software. $P<0.05$ was considered statistically significant.

\section{Results}

\section{Intraoperative and postoperative indicators of surgery}

The duration of surgery was $1.5-3 \mathrm{~h}$, with an average of $2 \mathrm{~h}$; the bleeding volume was $10-100 \mathrm{~mL}$, with an average of $40 \mathrm{~mL}$; radiotherapy was started 6 to $13 \mathrm{~d}$ postoperatively, with an average of $9.2 \mathrm{~d}$; postoperative complications included two cases of pure cyst, one case of lymphocyst with lower extremity edema, and six cases of lymphocyst associated with infection.

\section{Lymph node metastasis}

A total of 2937 PLNs were removed from the 96 patients, with an average number of 30.6 per patient, (range 17-53). Similarly, 758 PALNs were removed, with an average number of 7.9 per patient (range 6-22). The lymph node metastasis rate was $62.5 \%(60 / 96)$ and the CILN and/or PALN metastasis rate was $31.2 \%$ (30/96). Only 15 cases showed a MAD for CILN and/or PALN of more than $0.5 \mathrm{~cm}$. In 86 cases of squamous cell carcinoma, the lymph node metastasis rate was $58.1 \%(50 / 86)$ and the CILN and/or PALN metastasis rate was $24.4 \%$ (21/86); the latter rate included one case of PALN metastasis alone, two cases of CILN metastasis alone, and 18 cases of PLN metastasis below the total iliac. In 10 cases of non-squamous cell carcinoma, the tumor markers (CA125, CEA, and SCC-Ag) were within the normal range (data not shown); CT showed five cases of MAD $\geq 1 \mathrm{~cm}$ in the retroperitoneal lymph node, $0.5 \mathrm{~cm} \leq \mathrm{MAD}<$ $1.0 \mathrm{~cm}$ in three cases, and MAD $<0.5 \mathrm{~cm}$ in two cases, but the lymph nodes were extensively metastasized after the operation, and nine cases showed CILN and/or PALN metastasis. One case had metastasis of the mesorectal surface and right oviduct.

\section{Positive rate of retroperitoneal lymph node metastasis} judged by CT images of different MAD of lymph nodes CT revealed 172 visible lymph nodes in 96 patients. The postoperative pathology was used as the gold standard for judging retroperitoneal lymph node metastasis (Fig. 2). The MAD of the CT lymph nodes was used to determine the retroperitoneal lymph node metastasis (Fig. 2). The MAD was used to divide patients into a 0.5 $\mathrm{cm} \leq \mathrm{MAD}<1.0 \mathrm{~cm}$ group and a $\mathrm{MAD} \geq 1.0 \mathrm{~cm}$ group. The positive rate of lymph node metastasis was higher in the MAD $\geq 1.0 \mathrm{~cm}$ group (83.33\%) than in the $0.5 \mathrm{~cm} \leq$ MAD $<1.0 \mathrm{~cm}$ group $(26.82 \%)$, and the difference was statistically significant $(P<0.05)(=$ Table 1$)$.

\section{Critical value of CT lymph node MAD and serum SCC-Ag levels for evaluating retroperitoneal lymph node metastasis of cervical squamous cell carcinoma}

Of the 86 cases with cervical squamous cell carcinoma, 16 cases did not undergo SCC-Ag detection before the operation. The area under the receiver operating characteristic (ROC) curve for the CT lymph node MAD was 0.782 (95\% CI 0.706-0.859). The Youden index was the largest when the CT lymph node MAD was $1.0 \mathrm{~cm}$. The area under the ROC curve for serum SCC-Ag levels was 0.717 (95\% CI 0.594-0.841). The Youden index was the largest (0.456) when SCC-Ag was $5.2 \mathrm{ng} / \mathrm{mL}$ (Fig. 3). Spearmen correlation analysis of $\mathrm{MAD} \geq 1.0 \mathrm{~cm}$ and $\mathrm{SCC}-\mathrm{Ag} \geq 5.2 \mathrm{ng} / \mathrm{mL}$ was performed. The result suggested that the combination of these two indicators may further improve the predictive validity of lymph node metastasis.

\section{Efficacy of preoperative CT and/or serum SCC-Ag in assessing retroperitoneal lymph node metastasis of cervical squamous cell carcinoma}

The accuracy, specificity, and Youden index for a CT lymph node $\mathrm{MAD} \geq 1.0 \mathrm{~cm}$, together with $\mathrm{SCC}-\mathrm{Ag} \geq 5.2$ $\mathrm{ng} / \mathrm{mL}$, were $75.71 \%, 100 \%$, and 0.59 , respectively, and these values were significantly different from those of the CT lymph node MAD $\geq 1.0 \mathrm{~cm}$ group $(72.09 \%$, $80.56 \%$, and 0.47 , respectively) and the SCC-Ag $\geq 5.2 \mathrm{ng} /$ $\mathrm{mL}$ group $(71.43 \%, 68.97 \%$, and 0.42 , respectively) (Table 2, all $P<0.05$ ). Twenty-four patients with $\mathrm{CT}$ lymph node $\mathrm{MAD} \geq 1.0 \mathrm{~cm}$ and $\mathrm{SCC}-\mathrm{Ag} \geq 5.2 \mathrm{ng} / \mathrm{mL}$ (the double positive group) had lymph node metastasis after the operation, and 50\% (12/24) showed CILN and/or PALN metastasis. Eight patients with $\mathrm{CT}$ lymph node $\mathrm{MAD} \geq 1.0 \mathrm{~cm}$ and $\mathrm{SCC}-\mathrm{Ag}<5.2 \mathrm{ng} / \mathrm{mL}$ (the CT positive group) had CT positive lymph node metastasis, and five of the eight had postoperative lymph node metastasis. Fifteen patients with CT lymph node MAD $<1.0 \mathrm{~cm}$ and SCC-Ag $\geq 5.2 \mathrm{ng} / \mathrm{mL}$ (SCC-Ag positive group) had SCCAg positive lymph node metastasis, and six of these showed postoperative lymph node metastasis. Among the twenty-three cases with CT lymph node MAD $<1.0 \mathrm{~cm}$ and SCC-Ag $<5.2 \mathrm{ng} / \mathrm{ml}$, only six cases $(26.08 \%)$ had PLN metastasis below CILN after the operation. The double positive group was significantly different from the other groups (all $P<0.05$ ).

\section{High-risk factors for CILN and/or PALN metastasis in locally advanced cervical cancer}

Among the 96 patients, CT showed CILN and/or PALN MAD 0.5 to $1.0 \mathrm{~cm}$ in 11 patients, including 

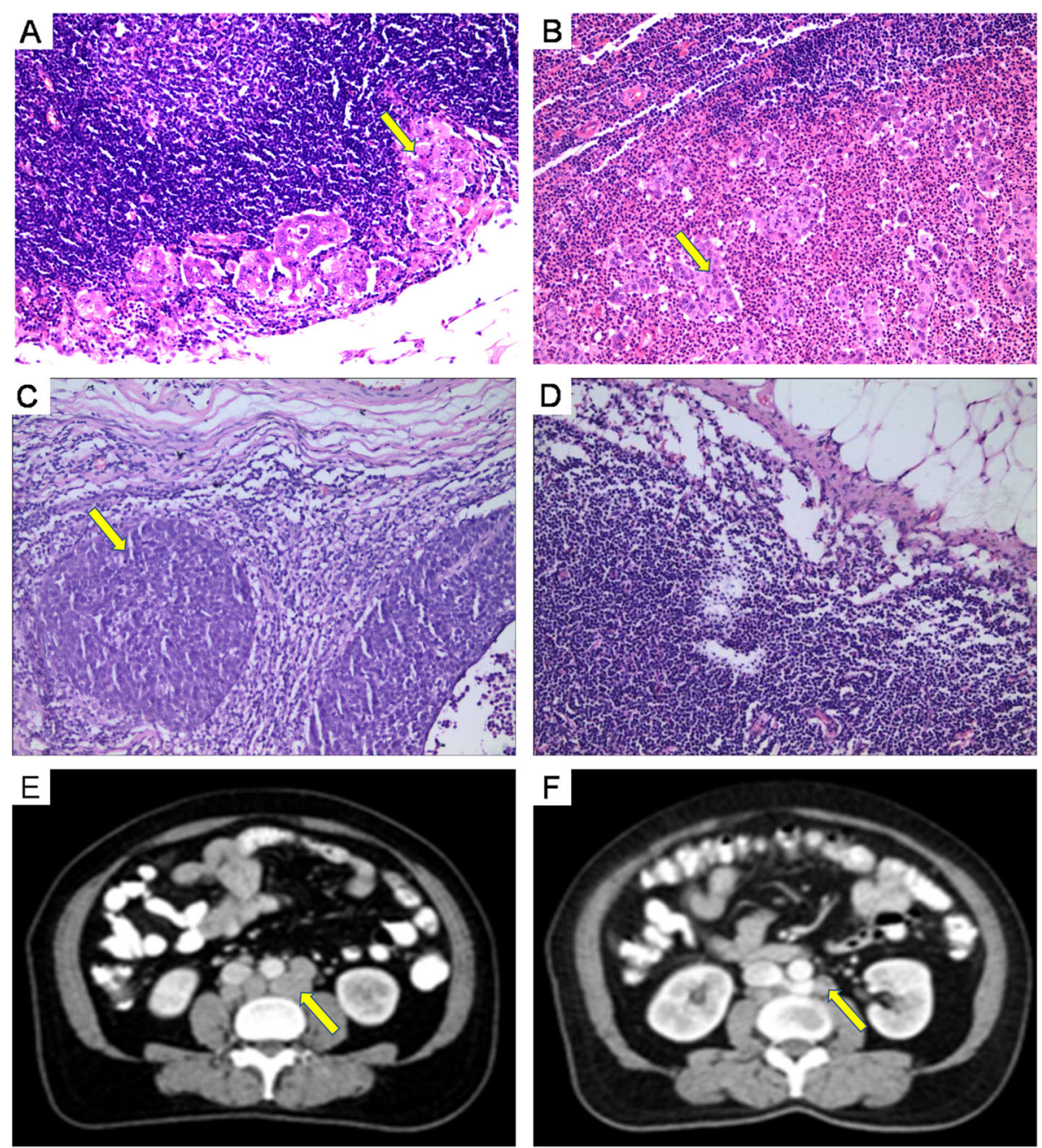

Fig. 2 Computed tomography (CT) scans and postoperative hematoxylin and eosin (H\&E) staining of responding lymph node. a. Lymph node metastasis of adenocarcinoma (yellow arrow) comfirmed by H\&E staining. b. Lymph node metastasis of adenosquamous carcinoma (yellow arrow) comfirmed by H\&E staining. c. Lymph node metastasis of squamous cell carcinoma (yellow arrow) comfirmed by H\&E staining. d. Normal lymph nodes. e. Measurement of MAD $(\geq 1.0 \mathrm{~cm})$ of the para-aortic lymph node. The yellow arrows showed the location of lymph node metastasis. The H\&E staining result was positive. $\mathbf{f}$. Measurement of MAD $(0.5-0.9 \mathrm{~cm})$ of the para-aortic lymph node. The yellow arrows showed the location of lymph node metastasis. The H\&E staining result was negative

seven patients with postoperative CILN and/or PALN metastases. CT showed CILN and/or PALN MAD $\geq 1.0 \mathrm{~cm}$ in 8 cases, and all patients showed postoperative CILN and/or PALN metastases. Correlation analysis showed that non-squamous cell carcinoma, PLN MAD $\geq 1.0 \mathrm{~cm}$ plus number $\geq 2$, and 1 PLN MAD $\geq 1.0 \mathrm{~cm}$ with CILN and/or PALN MAD $0.5-1.0 \mathrm{~cm}$ were risk factors for CILN and/or PALN metastasis (all $P<0.05)$ (Table 3).

\section{Discussion}

Lymph node metastasis is an independent prognostic factor for cervical cancer. Although CT, MRI, and PETCT have been widely used to evaluate the status of

Table 1 Comparison of positive rates of retroperitoneal lymph node metastasis judged by differences in computed tomography (CT) lymph node minimum axial diameter (MAD)

\begin{tabular}{|c|c|c|c|c|c|}
\hline \multirow[t]{2}{*}{ Group } & \multirow[t]{2}{*}{ Number } & \multicolumn{2}{|c|}{ Pathological results } & \multirow{2}{*}{$\begin{array}{l}\text { Percentage } \\
\text { (\%) }\end{array}$} & \multirow{2}{*}{$\begin{array}{l}P \\
\text { value }\end{array}$} \\
\hline & & Positive & Negative & & \\
\hline$M A D \geq 1.0 \mathrm{~cm}$ & 78 & 65 & 13 & 83.33 & 0.000 \\
\hline $0.5 \mathrm{~cm} \leq \mathrm{MAD}<1.0 \mathrm{~cm}$ & 82 & 22 & 60 & 26.82 & \\
\hline
\end{tabular}




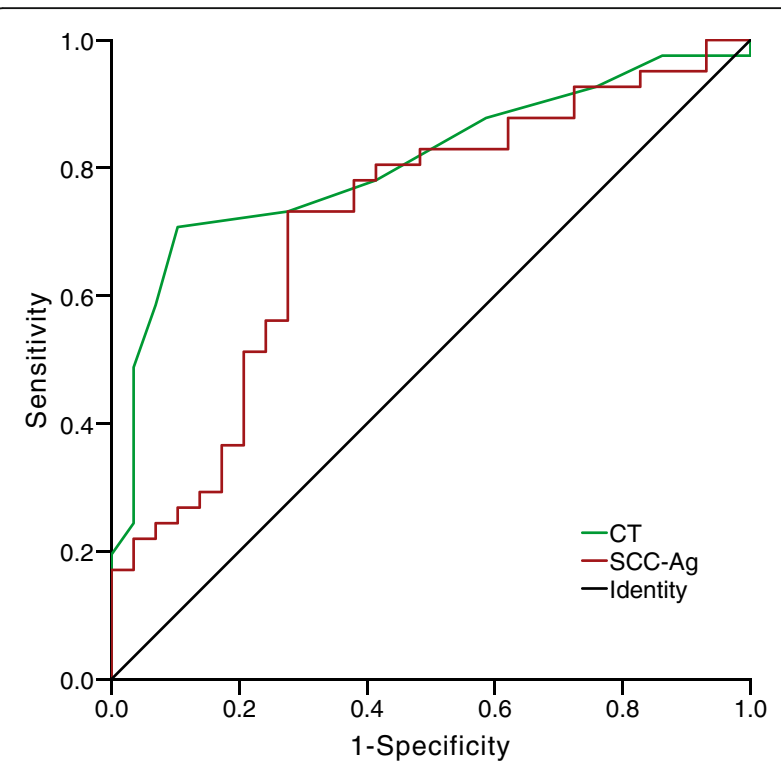

Fig. 3 The critical values of computed tomography (CT) lymph node minimum axial diameter (MAD) $(A \cup C=0.782)$ and serum squamous cell carcinoma antigen (SCC-Ag) (AUC $=0.717)$ levels in evaluating retroperitoneal lymph node metastasis of cervical squamous cell carcinoma

lymph nodes, imaging has several disadvantages, including insufficient sensitivity and accuracy; therefore, imaging-based radiotherapy has a certain degree of under- or over-treatment [6-11]. Surgical staging before radiotherapy can confirm lymph node metastasis and provide accurate guidance for follow-up treatment, but it increases the operative complications and hospitalization costs; therefore, the impact on prognosis needs further research $[14,15]$. For these reasons, the assessment of retroperitoneal lymph node status of locally advanced cervical cancer needs to be individualized, and strategies need to be developed for shunting patients with locally advanced cervical cancer determined by auxiliary examinations.

Serum SCC-Ag is an antigen with high specificity for the diagnosis of squamous cell carcinoma. Clinical diagnosis and prognosis of patients with squamous cell carcinoma are usually determined by the levels of SCC-Ag. For example, Duk studied 653 patients with squamous cervical carcinoma and found that the level of SCC-Ag was positively related to lymph nodes. The sensitivity and specificity of SCC-Ag $>1.9 \mathrm{ng} / \mathrm{ml}$ was $64.6 \%$ and $68.4 \%$, respectively [20]. Another study suggested that SCC-Ag $>4 \mathrm{ng} / \mathrm{ml}$ would raise the probability of lymph node metastasis by 4.2 folds $(\mathrm{OR}=4.212, P<0.05)$ [21]. Zhou et al. performed a meta-analysis of the value of serum SCC-Ag levels in the diagnosis of the lymph nodal metastasis in cervical cancer [22]. They found that the area under the ROC curve of SCC-Ag for pelvic lymph node metastasis was 0.71 , and the best cutoff value was $2.15 \mathrm{ng} / \mathrm{mL}$, with a sensitivity of $69.7 \%$ and a specificity of $66.4 \%$ [22]. In the present study, the area under the ROC curve of serum SCC-Ag levels in the retroperitoneal lymph node metastasis was 0.717 . When the SCC-Ag was $5.2 \mathrm{ng} / \mathrm{ml}$, the Youden index was the largest (0.456), and the corresponding sensitivity and specificity were 73.17 . \% and $68.97 \%$, respectively. Taken together, the findings of these studies indicate that SCCAg has a certain diagnostic value for lymph node metastasis of cervical squamous cell carcinoma. However, it is not ideal and needs to be combined with other indicators.

The combination of preoperative CT and serum SCCAg levels has been found to have a greater value in assessing retroperitoneal lymph node metastasis in a previous study of 197 cervical squamous cell carcinoma patients by $\mathrm{Xu}$ [23]. This study also showed that the combination of CT and SCC-Ag levels was a better way to evaluate the status of the retroperitoneal lymph node. In the present study, the accuracy, specificity, and Youden index of CT lymph node $\operatorname{MAD}(\geq 1.0 \mathrm{~cm})$ with SCC-Ag ( $\geq 5.2 \mathrm{ng} / \mathrm{mL})$ were $75.71 \%, 100 \%$, and 0.59 , respectively. Twenty-four patients in the group with CT lymph node $\mathrm{MAD} \geq 1.0 \mathrm{~cm}$ combined with $\mathrm{SCC}-\mathrm{Ag} \geq 5.2$ $\mathrm{ng} / \mathrm{mL}$ had metastasis rate of $100 \%$, whereas only six of 23 patients in the group with CT lymph node MAD < $1.0 \mathrm{~cm}$ and SCC-Ag $<5.2 \mathrm{ng} / \mathrm{mL}$ had PLN metastasis below CILN. Therefore, patients with CT lymph node MAD $\geq 1.0 \mathrm{~cm}$ and $\mathrm{SCC}-\mathrm{Ag} \geq 5.2 \mathrm{ng} / \mathrm{mL}$ should be treated with lymphadenectomy to clarify their lymph node metastasis status and provide accurate guidance for subsequent treatment. Patients with CT lymph node

Table 2 Efficacy of CT lymph node MAD and/or serum SCC-Ag in judging retroperitoneal lymph node metastasis in patients with locally advanced cervical squamous cell carcinom

\begin{tabular}{|c|c|c|c|c|c|c|c|}
\hline \multirow[t]{2}{*}{ Group } & \multirow[t]{2}{*}{ Case } & \multicolumn{2}{|c|}{ Pathological results } & \multirow{2}{*}{$\begin{array}{l}\text { Accuracy } \\
\text { (\%) }\end{array}$} & \multirow[t]{2}{*}{ Sensitivity(\%) } & \multirow{2}{*}{$\begin{array}{l}\text { Specificity } \\
\text { (\%) }\end{array}$} & \multirow{2}{*}{$\begin{array}{l}\text { Youden } \\
\text { index }\end{array}$} \\
\hline & & Positive & Negative & & & & \\
\hline CT lymph node $M A D \geq 1.0 \mathrm{~cm}+\mathrm{SCC}-\mathrm{Ag} \geq 5.2 \mathrm{ng} / \mathrm{mL}$ & 24 & 24 & 0 & $75.71^{*}$ & 58.54 & $100.0^{*}$ & $0.59^{*}$ \\
\hline$C T$ lymph node $M A D \geq 1.0 \mathrm{~cm}$ & 40 & 33 & 7 & 72.09 & 66.0 & 80.56 & 0.47 \\
\hline SCC-Ag $\geq 5.2 \mathrm{ng} / \mathrm{mL}$ & 39 & 30 & 9 & 71.43 & 73.17 & 68.97 & 0.42 \\
\hline
\end{tabular}


Table 3 The relationship between clinical pathological features of advanced cervical cancer and CILN and/or PALN metastasis

\begin{tabular}{|c|c|c|c|c|c|}
\hline \multirow[t]{2}{*}{ Factors } & \multirow[t]{2}{*}{ Case } & \multicolumn{2}{|c|}{ Post-operation CILN and/or PALN } & \multirow[t]{2}{*}{$x^{2}$ value } & \multirow{2}{*}{$\begin{array}{l}P \\
\text { value }\end{array}$} \\
\hline & & Positive & Negative & & \\
\hline \multicolumn{6}{|l|}{ Clinical stages } \\
\hline IB2 stage & 12 & 5 & 7 & & \\
\hline IIA2 - IIB stage & 51 & 15 & 36 & 0.700 & 0.705 \\
\hline IIIA - IIIB stage & 33 & 10 & 23 & & \\
\hline \multicolumn{6}{|l|}{ Pathological type } \\
\hline Squamous cell carcinoma & 86 & 21 & 65 & 15.011 & 0.000 \\
\hline Non-Squamous cell carcinoma & 10 & 9 & 1 & & \\
\hline \multicolumn{6}{|l|}{ Tumor diameter (cm) } \\
\hline$\leq 4$ & 33 & 11 & 22 & 0.102 & 0.750 \\
\hline$>4$ & 63 & 19 & 44 & & \\
\hline \multicolumn{6}{|l|}{ SCC-Ag (ng/mL) } \\
\hline$\geq 5.2$ & 39 & 14 & 25 & 3.653 & 0.056 \\
\hline$<5.2$ & 31 & 4 & 27 & & \\
\hline \multicolumn{6}{|l|}{$C T$ indicates PLN MAD $(\mathrm{cm})^{a}$} \\
\hline$<0.5$ & 7 & 1 & 6 & 1.315 & 0.518 \\
\hline $0.5-0.9$ & 34 & 5 & 29 & & \\
\hline$\geq 1.0$ & 36 & 9 & 27 & & \\
\hline \multicolumn{6}{|c|}{$C T$ indicates PLN MAD $0.5-1.0 \mathrm{~cm}$ (number) ${ }^{a}$} \\
\hline 1 & 24 & 4 & 20 & - & 1.000 \\
\hline$\geq 2$ & 10 & 1 & 9 & & \\
\hline \multicolumn{6}{|c|}{$C T$ indicates PLN MAD $\geq 1.0 \mathrm{~cm}$ (number) $^{\mathrm{a}}$} \\
\hline 1 & 26 & 3 & 23 & 9.046 & 0.003 \\
\hline$\geq 2$ & 10 & 6 & 4 & & \\
\hline \multicolumn{6}{|c|}{$C T$ indicates one PLN MAD $\geq 1.0 \mathrm{~cm} \pm$ MAD $0.5-1.0 \mathrm{~cm}$ CILN and/or PALN } \\
\hline Yes & 3 & 3 & 0 & - & 0.005 \\
\hline No & 26 & 3 & 23 & & \\
\hline
\end{tabular}

CILN common iliac lymph node, PALN para-aortic lymph node, PLN pelvic lymph node, SCC-Ag squamous cell carcinoma antigen, CT computed tomography, MAD minimum axial diameter. $P<0.05$ was considered statistically significant. ${ }^{a}$ Did not include patients whose CT showed CILN and/or PALN MAD $\geq 0.5 \mathrm{~cm}$

MAD $<1.0 \mathrm{~cm}$ and SCC-Ag $<5.2 \mathrm{ng} / \mathrm{mL}$ had a low lymph node metastasis rate, so they can be treated with radiotherapy and chemotherapy directly based on imaging.

For the extent of resection of retroperitoneal lymph nodes for locally advanced cervical cancer, as retroperitoneal lymph node surgery is pelvic and para-aortic lymph node dissection with a large surgical field, which can lead to a longer operative time and an increased probability of complications, so lymph nodes below the total iliac with MAD $<1.0 \mathrm{~cm}$ are not considered for routine inclusion in the resection range as they are located in the conventional treatment field [12, 13]. However, for enlarged lymph nodes with MAD $>1.0 \mathrm{~cm}$, the radical dose should be 60-65 Gy, whereas for lymph nodes with MAD $>2.0 \mathrm{~cm}$, the radical dose should be 65-70 Gy. Lymph nodes with MAD $>3.0 \mathrm{~cm}$ are difficult to cure by radiotherapy alone. Cosin et al. retrospectively analyzed 266 patients with cervical cancer who underwent retroperitoneal lymph node resection before radiotherapy [24]. They found comparable 10-year and 5-year disease-free survival rates for patients with enlarged or with small metastatic lymph node resection, and those patients who did not have enlarged lymph nodes removed all had recurrences. Other studies have shown that the removal of swollen positive lymph nodes is beneficial to the survival of patients with cervical cancer [25]. Therefore, we recommend the resection and sampling of enlarged lymph nodes below the common iliac gland with the MAD greater than $1.0 \mathrm{~cm}$.

For CILN and/or PALN, the metastatic status will determine the radiotherapy regimen. A comprehensive assessment should be performed based on preoperative auxiliary examinations, such as imaging data and tumor markers. Shim et al. showed that the diagnosis of PALN metastasis by PET-CT and tumor diameter $\geq 5 \mathrm{~cm}$ were 
independent factors affecting PALN metastasis [26]. His recommendation is that patients with a tumor diameter of $\geq 5 \mathrm{~cm}$ and PET-CT indicative of PALN metastasis should undergo the PALN resection, while radiotherapy and chemotherapy can be used directly in the low-risk and high-risk groups. In the present study, nonsquamous cell carcinoma, PLN MAD $\geq 1.0 \mathrm{~cm}$ plus number $\geq 2$, and 1 PLN MAD $\geq 1.0 \mathrm{~cm}$ with CILN and/or PALN MAD $0.5-1.0 \mathrm{~cm}$ were risk factors for CILN and/ or PALN metastasis, and our recommendation was resection of the lymph nodes below the common iliac gland and CILN/PALN. For PLNs with a MAD of 0.5$1.0 \mathrm{~cm}$ below the common iliac gland, the CILN and/or PALN metastasis rate did not change significantly regardless of the number of lymph nodes or the existence of CILNs and/or PALNs with MAD between $0.5-1.0 \mathrm{~cm}$, so these PLNs can be directly treated with chemoradiotherapy according to the imaging. PALN also did not require extended field radiotherapy to avoid adverse reactions.

The present study has some limitations. One is that the sample size was small, and the operation was performed with PLN and PALN resection. Further study is also needed in patients with only one CT lymph node $\mathrm{MAD} \geq 1.0 \mathrm{~cm}$ and the serum SCC-Ag $<5.2 \mathrm{ng} / \mathrm{mL}$, as well as SCC-Ag $\geq 5.2 \mathrm{ng} / \mathrm{mL}$ and retroperitoneal lymph node MAD $<1.0 \mathrm{~cm}$, to determine whether PET-CT should be performed first to understand lymph node metastasis to determine the subsequent treatment. The effect of surgical staging on subsequent chemotherapy and prognosis also needs further study to confirm the safety and feasibility of laparoscopic retroperitoneal lymph node dissection, so that patients will experience an effective treatment and have a longer survival time while enjoying a good quality of life.

\section{Conclusions}

The patients with CT lymph node MAD $\geq 1.0 \mathrm{~cm}$ and SCC-Ag $\geq 5.2 \mathrm{ng} / \mathrm{mL}$, as well as high risk factors for CILN and/or PALN metastasis, should undergo resection of enlarged lymph nodes below the common iliac gland, as well as lymphadenectomy of CILN/PALN to reduce tumor burden and to clarify lymph node metastasis status to provide accurate guidance for the follow-up treatment. Patients with CT lymph node MAD $<1.0 \mathrm{~cm}$ and SCC- $\mathrm{Ag}<5.2 \mathrm{ng} / \mathrm{mL}$ may be treated with chemoradiotherapy directly based on imaging, given the low lymph node metastasis rate in these patients.

\footnotetext{
Abbreviations

FIGO: International Federation of Gynecology and Obstetrics; PLN: Pelvic lymph node; PALN: Para-aortic lymph node; CILN: Common iliac lymph node; CT: Computed tomography; MRI: Magnetic resonance imaging; PETCT: Positron emission tomography/computed tomography; SCCAg: Squamous cell carcinoma antigen; H\&E: Hematoxylin and eosin; RTOG: Radiation Therapy Oncology Group; MAD: Minimum axial diameter;
}

RLUs: Relative luminescence units; IMRT: Intensity-Modulated Radiation Therapy; ROC: Receiver operating characteristic

\section{Acknowledgements}

None.

\section{Authors' contributions}

$W L$ and $L X$ designed the study, collected the data, analyzed the data, and drafted the manuscript. QLZ and $H L$ collected the data. MLZ analyzed the data and drafted the manuscript. MRL, WJ, and YNW helped to analyze the data and revised the manuscript. WC conceived of the study and revised the manuscript. All authors read and approved the final manuscript.

\section{Funding}

None.

Availability of data and materials

The data that support the findings of this study are available from the corresponding author upon reasonable request.

\section{Declarations}

Ethics approval and consent to participate

The study was approved by the Ethics Committee of the Hunan Maternal and Child Health Hospital. The written informed consent to participate was provided by all patients.

Consent for publication

Not Applicable.

\section{Competing interests}

The authors declare that they had no competing interests.

\section{Author details}

${ }^{1}$ Department of Gynecology, Hunan Maternal and Child Health Hospital, Changsha, Hunan, China. ${ }^{2}$ Department of Pathology, Hunan Maternal and Child Health Hospital, Changsha, Hunan, China. ${ }^{3}$ Department of Oncology, Jiangxi Maternal and Child Health Hospital, Nanchang, Jiangxi, China.

Received: 9 March 2020 Accepted: 18 April 2021

Published online: 01 May 2021

\section{References}

1. Wright JD, Matsuo K, Huang Y, Tergas Al, Hou JY, Khoury-Collado F, et al. Prognostic performance of the 2018 International Federation of Gynecology and Obstetrics Cervical Cancer Staging Guidelines. Obstet Gynecol. 2019; 134(1):49-57. https://doi.org/10.1097/AOG.0000000000003311.

2. Heller PB, Malfetano JH, Bundy BN, Barnhill DR, Okagaki T. Clinicalpathologic study of stage IIB, III, and IVA carcinoma of the cervix: extended diagnostic evaluation for paraaortic node metastasis--a gynecologic oncology group study. Gynecol Oncol. 1990;38(3):425-30. https://doi.org/1 0.1016/0090-8258(90)90085-Y.

3. Matsuo K, Shimada M, Saito T, Takehara K, Tokunaga H, Watanabe $Y$, et al. Risk stratification models for Para-aortic lymph node metastasis and recurrence in stage IB-IIB cervical cancer. J Gynecol Oncol. 2018;29(1):e11. https://doi.org/10.3802/jgo.2018.29.e11.

4. Sakuragi N, Satoh C, Takeda N, Hareyama H, Takeda M, Yamamoto R, et al. Incidence and distribution pattern of pelvic and paraaortic lymph node metastasis in patients with stages IB, IIA, and IIB cervical carcinoma treated with radical hysterectomy. Cancer. 1999;85(7):1547-54. https://doi.org/10.1 002/(SICI)1097-0142(19990401)85:7<1547::AID-CNCR16>3.0.CO;2-2.

5. Huang L, Huang ZJ, Gao K. Advances in research on the treatment of cervical cancer with Para-aortic extension field radiotherapy. Chin J Obstet Gynecol. 2017;52(10):717-20.

6. Chung $\mathrm{HH}$, et al. Role of magnetic resonance imaging and positron emission tomography/computed tomography in preoperative lymph node detection of uterine cervical cancer. Am J Obstet Gynecol. 2010;203(2):156. e1-5.

7. Zhang J, Ren C, Xue HD, Zhou HL, Sun ZY, Jin ZY. Value of diffusionweighted imaging in diagnosis of lymph node metastasis in patients with 
cervical cancer. Zhongguo Yi Xue Ke Xue Yuan Xue Bao. 2014;36(1):73-8. https://doi.org/10.3881/j.issn.1000-503X.2014.01.014.

8. Shen G, Zhou H, Jia Z, Deng H. Diagnostic performance of diffusionweighted MRI for detection of pelvic metastatic lymph nodes in patients with cervical cancer: a systematic review and meta-analysis. Br J Radiol. 2015;88(1052):20150063. https://doi.org/10.1259/bjr.20150063.

9. Liu B, Gao S, Li S. A comprehensive comparison of CT, MRI, positron emission tomography or positron emission tomography/CT, and diffusion weighted imaging-MRl for detecting the lymph nodes metastases in patients with cervical Cancer: a meta-analysis based on 67 studies. Gynecol Obstet Investig. 2017;82(3):209-22. https://doi.org/10.1159/000456006.

10. Brunette LL, Bonyadlou S, Ji L, Groshen S, Shuster D, Mehta A, et al. Predictive value of FDG PET/CT to detect lymph node metastases in cervical Cancer. Clin Nucl Med. 2018;43(11):793-801. https://doi.org/10.1097/RLU. 0000000000002252

11. Fleming S, Cooper RA, Swift SE, Thygesen HH, Chowdhury FU, Scarsbrook AF, et al. Clinical impact of FDG PET-CT on the management of patients with locally advanced cervical carcinoma. Clin Radiol. 2014;69(12):1235-43. https://doi.org/10.1016/j.crad.2014.07.006.

12. Del Pino M, et al. Laparoscopic lymphadenectomy in advanced cervical cancer: prognostic and therapeutic value. Int J Gynecol Cancer. 2013;23(9): 1675-83. https://doi.org/10.1097//GC.0000000000000000.

13. Vazquez-Vicente $\mathrm{D}$, et al. Retroperitoneal laparoscopic Para-aortic lymphadenectomy in Para-aortic staging of locally advanced cervical Cancer. J Minim Invasive Gynecol. 2018;25(7):1142-3. https://doi.org/10.101 6/j.jmig.2018.01.033.

14. Lee J-Y, Kim Y, Lee TJ, Jeon YW, Kim K, Chung HH, et al. Cost-effectiveness of Para-aortic lymphadenectomy before chemoradiotherapy in locally advanced cervical cancer. J Gynecol Oncol. 2015;26(3):171-8. https://doi. org/10.3802/jgo.2015.26.3.171.

15. Pomel C, Martinez A, Bourgin C, Beguinot M, Benoit C, Naik R, et al. Survival effect of laparoscopic Para-aortic staging in locally advanced cervical cancer: a retrospective cohort analysis. Bjog. 2017;124(7):1089-94. https://doi.org/1 0.1111/1471-0528.14492.

16. Gold MA, Tian C, Whitney CW, Rose PG, Lanciano R. Surgical versus radiographic determination of Para-aortic lymph node metastases before chemoradiation for locally advanced cervical carcinoma: a gynecologic oncology group study. Cancer. 2008;112(9):1954-63. https://doi.org/10.1002/ cncr.23400.

17. Wei J, et al. Clinical effect of lymphadenectomy under laparoscopy for locally advanced cervical Cancer. Pract J Cancer. 2016;31(12):2066-2068, 2072.

18. Wei J, Zeng S, Liang M. Evaluation of CT scanning in the diagnosis of pelvic lymph node metastasis in gynecological malignancies. Pract J Cancer. 2014.

19. Lekskul N, Charakorn C, Lertkhachonsuk AA, Rattanasiri S, Ayudhya NIN. The level of squamous cell carcinoma antigen and lymph node metastasis in locally advanced cervical Cancer. Asian Pac J Cancer Prev. 2015;16(11):471922. https://doi.org/10.7314/APJCP.2015.16.11.4719.

20. Duk JM, Groenier KH, de Bruijn HW, Hollema H, ten Hoor KA, van der Zee AG, et al. Pretreatment serum squamous cell carcinoma antigen: a newly identified prognostic factor in early-stage cervical carcinoma. J Clin Oncol. 1996;14(1):111-8. https://doi.org/10.1200/JCO.1996.14.1.111

21. Feng SY, Zhang YN, Liu JG. Risk factors and prognosis of node-positive cervical carcinoma. Chin J Cancer. 2005;24(10):1261-6.

22. Zhou Z, Li W, Zhang F, Hu K. The value of squamous cell carcinoma antigen (SCCa) to determine the lymph nodal metastasis in cervical cancer: a metaanalysis and literature review. PLoS One. 2017;12(12):e0186165. https://doi. org/10.1371/journal.pone.0186165.

23. Xu D, Wang D, Wang S, Tian Y, Long Z, Ren X. Correlation between squamous cell carcinoma antigen level and the Clinicopathological features of early-stage cervical squamous cell carcinoma and the predictive value of squamous cell carcinoma antigen combined with computed tomography scan for lymph node metastasis. Int J Gynecol Cancer. 2017;27(9):1935-42. https://doi.org/10.1097/IGC.0000000000001112.

24. Cosin JA, Fowler JM, Chen MD, Paley PJ, Carson LF, Twiggs LB. Pretreatment surgical staging of patients with cervical carcinoma: the case for lymph node debulking. Cancer. 1998;82(11):2241-8. https://doi.org/10.1002/(SICl)1 097-0142(19980601)82:11<2241::AID-CNCR20>3.0.CO;2-T.

25. Somashekhar SP. Does debulking of enlarged positive lymph nodes improve survival in different gynaecological cancers? Best Pract Res Clin Obstet Gynaecol. 2015;29(6):870-83. https://doi.org/10.1016/j.bpobgyn.2015. 04.010.
26. Shim SH, Kim DY, Lee SJ, Kim SN, Kang SB, Lee SW, et al. Prediction model for Para-aortic lymph node metastasis in patients with locally advanced cervical cancer. Gynecol Oncol. 2017;144(1):40-5. https://doi.org/10.1016/j. ygyno.2016.11.011.

\section{Publisher's Note}

Springer Nature remains neutral with regard to jurisdictional claims in published maps and institutional affiliations.

\section{Ready to submit your research? Choose BMC and benefit from:}

- fast, convenient online submission

- thorough peer review by experienced researchers in your field

- rapid publication on acceptance

- support for research data, including large and complex data types

- gold Open Access which fosters wider collaboration and increased citations

- maximum visibility for your research: over $100 \mathrm{M}$ website views per year

At BMC, research is always in progress.

Learn more biomedcentral.com/submissions 